\title{
As redes femininas de oposição à ditadura civil-militar
}

\section{The women's network contributions against the military dictatorships}

\author{
Maria Cláudia Badan RIBEIRO \\ Universidade Estadual de Campinas (UNICAMP)
}

RESUMO: Este artigo pretende dar uma contribuição para se pensar a oposição política de mulheres ao regime militar no Brasil. Nosso objetivo foi mostrar a luta em seu interior, suas tensões e as formas como estas mulheres militantes se moveram sob este contexto para atuar, exigir e transgredir o muro de suas casas tecendo solidariedades e alianças. Suas lutas, compromissos e convicções políticas se forjaram na guerra e no enfrentamento às violências e arbitrariedades cometidas pelo governo repressor.

PALAVRAS-CHAVE: Mulheres. Ditadura. Luta armada. Redes de apoio e solidariedade.

ABSTRACT: This article aims to make a contribution to think the women political opposition against the military regime in Brazil. Focusing on the movement inside, around its tensions and resistance activities, this paper will explore the powerful of the solidarity networks as a protest against the Brazilian authoritarian regime.

KEYWORDS: Women. Dictatorship. Armed struggle. Solidarity and support networks.

\section{Introdução}

Este texto procura trazer um mapa do território militante com relação à atividade política de mulheres que viveram a ditadura civil-militar no Brasil, mostrando o que ficou oculto no relato das sobreviventes, rompendo com os discursos mistificadores relacionados à luta armada e à guerrilheira de armas na mão, e transformando as ações de luta das mulheres em chaves de identificação histórica, lugar, direção. Por trás do estereótipo do guerrilheiro se perdem muitos aspectos das vidas privadas que excederam o âmbito da guerrilha, e vão compor naquele contexto, o que definimos como redes de solidariedade, redes de apoio logístico ou simplesmente pequenos e corajosos gestos de ajuda na luta contra a ditadura.

Pretendemos, neste texto, mostrar as dinâmicas e diferentes práticas de guerra e ao mesmo tempo fugir de um olhar dicotômico dos papéis entre homens e mulheres enquanto polos de contradição. O que nos interessa é como afirmou Alain Touraine, "descobrir como as mulheres inventam-se como sujeito, saindo desse dualismo eterno 
[...] e redefinindo-se, reinventando-se", para além deste antagonismo (TOURAINE, 2004, p. 170).

Dentro e fora das organizações de luta armada, as mulheres desempenharam uma variedade de funções que ganharam pouca ou quase nenhuma ênfase na historiografia. A resistência à ditadura se configurou como uma série de atos isolados, não premeditados e que se organizaram a partir de decisões pessoais, ou da cumplicidade e solidariedade de familiares, conterrâneos, ou de pessoas que estavam contra a violência de Estado. Suas atividades nem sempre foram lidas pela repressão como "subversivas" ou "políticas", e muitas delas não figuraram como suspeitas nos documentos da repressão, nem tiveram prisão preventiva decretada.

Estas formas ocultas e pouco conhecidas da resistência buscaram a sobrevivência e a conservação de certos graus de autogestão. Muitas vezes essas resistências individuais da cotidianidade persistiram por largos períodos, encontrando novas válvulas de escape na luta contra a repressão. Foi uma oportunidade que mulheres encontraram para se opor aos militares fazendo parte de movimentos pessoais dispersos, solidários e silenciosos que ao serem conhecidos, permitem compreender a riqueza e a complexidade que representaram.

Nossa compreensão da resistência não se centra nem nas organizações formais, nem no protesto aberto essencialmente, mas, explora e se refere a outras maneiras, não menos dramáticas do que a luta frontal, pública e armada: os espaços de luta que a invisibilidade, prorrogativa histórica da figura feminina, engendrou. São estas forças que ao não poder escapar da perseguição implacável dos militares, em um contexto de profunda vulnerabilidade, assimetria e terror resistiram através de formas, movimentos, gestos e atos sutis.

De longe estas atitudes parecem não se opor à repressão, pois muitas delas aconteceram de maneira clandestina e aparentemente não interromperam o transcurso normal da vida. Representaram, no entanto, gestos que significaram a diferença entre a vida e a morte. Estas resistências também não foram homogêneas e basearam-se em distintos conhecimentos de seus autores sobre as dinâmicas locais da guerrilha, como também pela conduta assumida pelas forças da repressão em determinados espaços do cotidiano. Não deixaram, portanto, de se inscreverem como ações concretas de 
enfrentamento, negando-se a obedecer as ordens da ditadura, elaborando estratégias de proteção, conservação e mobilização da resistência à ditadura.

Falar desta retaguarda implica em saber como podemos ler, interpretar e entender a conduta política destas parcelas de oposição, descobrindo suas estratégias de sobrevivência e de luta, em especial de mulheres que atuaram sozinhas e/ou em redes, naqueles anos. A resistência individual se configura como uma forma de resistência não oficial, não pública, não estruturada. Como afirma Scott, "quando uma dominação é tão forte, o mais provável é que ela produza um discurso oculto", este não compartilhar o controle da vida cotidiana e a imposição de uma ordem militar (SCOTT, 2000, p. 52).

Segundo Scott, este discurso oculto é uma segunda forma de linguagem política que sob o olhar intimidador do poder, está na origem do surgimento de uma cultura política dissidente. Ele é a política do anonimato que se exerce publicamente, são formas de resistência muito discretas que recorrem a formas indiretas de expressão (SCOTT, 2000, p. 43-44). Ao se referir à formação de uma cultura política dissidente em contextos de dominação e de repressão, estamos inevitavelmente lidando com noções que envolvem unanimidade, legitimidade, conflito e adaptação à realidade dos sujeitos históricos.

Olhando-se para a ditadura no Brasil e para as suas formas de consolidação, onde a concreta coerção pela violência conviveu com as ambiguidades do regime diante das normas do poder legal (AQUINO, 2004, p. 91), podemos pensar nas margens de negociação deixadas pelo regime ou encontradas pelos opositores para sua atuação política. Se o discurso público da ditadura teve sua origem no ocultamento, na eufemização, na estigmatização, e numa ideia construída de "unanimidade" e de concordância com o regime, o processo de dominação que ele exerceu, também não produziu uma conduta pública homogênea. É importante por isso, resgatar onde esta resistência ideológica existiu, como este anonimato político funcionou de modo invertido e como por detrás da adaptação às ordens da ditadura funcionou todo um trabalho de negação do regime, por meio de um discurso aparente de submissão.

Ao fazer este exercício, evita-se também de confinar outras experiências de oposição a espaços fechados e coesos. Esta aparência de unanimidade, que se estende aos "subordinados", parece cumprir um controle ainda maior sobre eles, silenciando-os e impedindo que se desvende tanto o discurso de aceitação construído pela ditadura, 
como os 'recursos de fala', e a insubordinação dos pequenos gestos da oposição. Pois se nega a priori a possibilidade de uma ação autônoma por parte deles e daqueles que se reuniram por iniciativa própria. "É sempre mais tentador interpretar o uso das forças coercitivas do que aproveitar uma fonte original de poder e de legitimidade que perdeu a sua força”. (SCOTT, 2000, p. 74).

Para Scott (2000), é importante esclarecer o conceito de dominação evitando a naturalização das relações de poder, e procurando encontrar o que ficou escondido da superfície. Sua preocupação é a de mostrar quais atores específicos e posições sociais específicas chegam a ser portadores deste discurso oculto. E no nosso caso, isto implica em rever os acordos, a legitimação da ditadura, as relações de poder e consentimento da sociedade em relação ao regime.

Geralmente os "dominados", tem por sua vez, "boas razões para contribuir em preservar essas aparências ou pelo menos, para não contradizê-las abertamente". (SCOTT, 2000, p. 97). Por isso, a reação, a oposição são lugares complexos. A resistência surge como ele diz, não apenas da apropriação material, mas também:

[d]a sistemática humilhação pessoal que caracteriza a exploração, e aquilo que produz indignação profunda, ressentimento $\mathrm{e}$ invisibilidade. Porque dignidade é ao mesmo tempo atributo privado e público. (SCOTT, 2000, p.142).

Ao mesmo tempo, a solidariedade que esta época despertou, não representou apenas um ato de caridade indiferenciada de alguns setores, mas um apoio a forças que agiram movidas por ideais revolucionários, alimentando-se e movimentando-se enquanto parte também desta resistência.

De qualquer modo que olhemos para este discurso oculto, ele não deixa de se constituir num ato de afirmação direta frente ao poder, de ser uma maneira de contestar o regime. E se queremos entender o processo de desenvolvimento da resistência, é indispensável analisar a criação destes espaços marginais, onde homens e mulheres estiveram presentes. Apenas especificando como se elabora e se definem estes espaços será possível passar do sujeito rebelde individual - uma construção abstrata - à socialização das práticas e discursos de resistência, reconhecendo seu poder de interferência na realidade. 
O discurso oculto é o resultado das relações de poder, espaços sociais de conquista, e, enquanto afirmação de forças oprimidas são "rituais de inversão da linguagem reprimida ou suprimida num outro âmbito de poder". (SCOTT, 2000, p. 205). E é justamente por este discurso oculto estar sujeito às relações de poder, que ele pode se apresentar como manipulação e como enfrentamento. Pode ser o "espetáculo de afirmação dos de baixo", como atuação "dos de cima" realizado à margem da sociedade, como foi a prática da ditadura com o uso de centros clandestinos de tortura e assassinatos, de subornos, falsificação, ocultação de informações. Por isso este discurso, tanto pode funcionar como crítica ao poder, como pode servir como o seu instrumento.

Neste artigo, queremos mostrar como este discurso oculto representou uma postura de enfrentamento contra a ditadura para as mulheres e como ao mesmo tempo ele mostrou sua face contraditória ao "adulterar" a memória pelos silêncios, pela problemática que existe entre memória e identidade, pelo difícil olhar interior de si mesmo no tempo, pelas margens de negociação com esta memória e pelas situaçõeslimite vividas por estas mulheres. Este artigo será, portanto, uma tentativa de fazer o inventário destes arquivos do silêncio (LE GOFF, 2005, p. 109), trazendo à tona as diferentes formas de expressões desta resistência, as fronteiras e alteridades que se instalaram na luta e os tipos de subjetividade que nela transpareceram. A partir dos testemunhos destas protagonistas temos muitos exemplos do caráter ambivalente e contraditório de suas realidades, suas motivações, suas versões, justamente porque estas fontes orais, como definiu René Jara, constituem-se numa "narração de urgência" e ao mesmo tempo trazem uma "dimensão moralizadora", diante da experiência de repressão, pobreza, exploração, marginalização, crime e luta (BEVERLEY, 1987).

\section{O controle da vida pelo Estado}

Nosso propósito é o de refletir sobre o papel das mulheres nas redes revolucionárias, ampliando a ideia da guerrilheira armada, mostrando outros perfis de militância, suas práticas e o significado que tiveram no contexto em que se inscreveram. A partir de um longo trabalho de campo, tentamos mostrar não apenas a inserção feminina na luta armada, mas o caráter político das ações cotidianas, ações como as de resgatar, proteger e ressignificar a vida, práticas que não estão inscritas nas agendas 
políticas organizativas e públicas, senão dependeram em grande parte das rotinas cotidianas, da agência individual e da contingência.

Para entender a dimensão microssocial destas ações, é necessário situá-las também como parte das dimensões estruturais em que estiveram inscritas, pois a solidificação destas redes de apoio e de ajuda foi também resultado do tipo de inserção da ditadura civil-militar na sociedade brasileira. O golpe militar de 1964 trouxe um repertório de violência, controle e regulação da vida cotidiana. Diferentes esferas da vida social foram controladas, moldadas e disciplinadas à luz de um projeto de ordem homogêneo que exacerbou as diferenças de gênero, instaurou hierarquias raciais, impondo novas formas de segregação e discriminação. Nesta nova "gramática social" a ditadura criou um código de conduta específico, lançando mão de sanções, exclusões e instaurando o que na sua compreensão representava o bem, o mal, a ordem, a desordem, a retidão e o desvio. O "feminino" e o "masculino" foram tipificados e o controle da ditadura foi realizado tanto sobre o público, como sobre o privado, sobre as relações afetivas, familiares, na relação com os filhos, vizinhos, trabalho e em outras relações sociais.

A conversão obrigatória aos ditames morais da ditadura encontrou no corpo o local privilegiado de informações "subversivas", no corte de cabelo, no vestuário, no penteado, na barba por escanhoar. E foi nas relações entre mulheres e na normatividade que se refere ao feminino onde se viu uma regulação concreta, ordenada, drástica e sistemática, punida com humilhação pública e com o estigma social da mulher transgressora, da rebelde, da mulher que passou a ocupar o espaço público varrendo para longe a ideia do "sexo frágil". Tais comportamentos eram considerados como afrontas não apenas ao patriarcalismo da sociedade, mas à ditadura e ao pensamento conservador castrense. Verifica-se por isso, que na origem da militância de muitas mulheres, a oposição à ditadura também teve como um dos marcos a liberação dos costumes, o "despertar de uma consciência feminina" que vinha se dando anos antes, não sem dificuldades, e em consonância com as mudanças econômicas e opostas ao conservadorismo da Igreja Católica.

A ideia da ditadura foi a de dispersar as pessoas dos espaços de sociabilidade. Estar em grupo passou a ser visto como sinal de conspiração. As pessoas acostumadas a passear pelas ruas, a deixar a porta aberta como sinal de convite aos amigos foram 
paulatinamente sendo obrigadas à intimidade do lar (que podia ser também quebrada pelas forças da ordem a qualquer instante), e à urgência do trabalho. Para uma ditadura em que o delito de opinião podia ser ume mera indisposição contra o regime, as consequências para quem se colocasse na oposição, podiam ser drásticas, num regime condenava mesmo as vias moderadas, num maniqueísmo absoluto.

Assim, quem se solidarizasse com a dor alheia, com os danos morais causados a amigos, vizinhos, conhecidos, parentes também se tornava alvo da ditadura, e de sua maneira de desacreditar os chamados "inimigos do regime" com intimidação, detenção, castigo público ou morte. A própria tradição fúnebre, o espaço do luto sofreu interferência da ditadura, quando os familiares dos militantes políticos, não podiam velar seus corpos, pela regulação do velório, pela delimitação de horário, pelas intimidações da polícia, com a presença de caixões lacrados ou simplesmente pela ausência deles. A dor pessoal perdeu assim, sua função social, transformando-se num sistema de punições exclusivo.

As subjetividades indesejadas pela ditadura foram punidas com a tortura, a morte, manipulação, ou reeducadas com a prisão, ou com as atitudes de advertência do regime. Mas, se a ditadura colocou em suspenso o diálogo e a espontaneidade das pessoas, disciplinando a vida com a ameaça onipresente da violência física, que sentimento de revolta ou inconformismo ela provocou? Quem foi, afinal, o público de todas estas cerimônias? Quais foram as engenhosas maneiras de atuar daqueles que não sendo alvos diretos da ditadura, discordaram de seus métodos?

\section{O discurso oculto das redes de ajuda e solidariedade}

A militância política é resultado de um processo em que vários fatores estão envolvidos. Não podemos desconsiderar o contexto histórico, nem as matrizes culturais e ou educacionais que alimentaram determinadas ideologias e organizaram determinadas formas de combate. Tampouco a existência de uma organização ou de um partido como uma fonte de inspiração moral e de ensino para muitos quadros. O engajamento político envolveu, porém outras dimensões que não fizeram parte essencialmente do partido. Ele nasceu de uma conversa, de uma discussão, de um interesse, de um sentimento. 
Olhando por este prisma, a atuação das mulheres na ditadura dependeu tanto das orientações dos grupos aos quais elas se ligaram, quanto das circunstâncias que se apresentaram. A militância foi parte também de um movimento espontâneo, gerado pela repulsa tanto aos tabus e ao ceticismo machista da época, como à falta de liberdade imposta pelo regime. E no que se refere às mulheres, a ditadura representou para elas, um reino da astúcia na vida cotidiana.

O recorte de classe nesta experiência mostra mais a disposição individual das pessoas na luta contra a ditadura do que uma posição clássica nas relações de produção, Há uma multiplicidade de perfis que compuseram esta oposição. Mulheres provenientes de famílias de latifundiários, da alta burguesia assim como mulheres pobres que dividiram a vida em cortiços são alguns dos exemplos que a luta contra o regime colocou lado a lado.

Sylvia de Montarroyos originária da alta aristocracia pernambucana teve que se adequar à radical mudança de hábitos, para se acomodar à vida dura da clandestinidade, vivendo em aparelhos, numa carência quase que absoluta de tudo (MONTARROYOS, 2013). Ignez Maria, filha de uma rica família proprietária de terras no estado Rio Grande do Sul, além dos constantes deslocamentos entre Brasil e Uruguai, transportando documentos, fez curso de paraquedismo, que segundo ela, representava mais uma das rupturas com o comportamento tradicional (MARIA, 2013).

Um dos grandes apoios da militante Maria Conceição Sarmento Coelho da Paz, por exemplo, era a proprietária da SECURIT, importante empresa do ramo de móveis para escritório na cidade de São Paulo. Ela não só hospedava a militante em sua casa, como lhe deu mil dólares quando Maria da Conceição deixou o país em direção a Cuba (informação verbal) ${ }^{1}$. E é justamente dentro desta dinâmica de ajuda tanto individual quanto coletiva que a militância foi se formando e se difundindo. Dado que a atividade política explícita estava proibida, a resistência se realizou pelas redes informais.

Uma avaliação apressada desta experiência de luta poderia nos forçar a concluir que sob as botas dos generais, pouca oposição existiu e ela se restringiu a momentos excepcionais de explosão popular. Estaríamos assim, omitindo as formas de organização e de ação que existiram nas franjas de um sistema de tirania e de opressão,

\footnotetext{
${ }^{1}$ PAZ, Carlos Eugênio. Entrevista. [jan. 2013]. Entrevistador: Autora. Paris, 2013.
} 
e não atentando para a intenção dos gestos e para "as estruturas invisíveis dentro das quais este invisível se articulou". (GINSBURG, 1991, p. 178).

É importante destacar a vontade destas mulheres e suas escolhas, pois elas não agiram nem por gosto de aventura nem atuaram irrefletidamente. Não foram inocentes úteis, ou esposas complacentes como os documentos da repressão quiseram mostrar. A repressão usava como arma o juízo de valor da maioria da sociedade brasileira da época: a de que a mulher acompanhava o marido. E isto também se reproduzia nos processos da Justiça Militar. Vera Engracia Gama de Oliveira, militante da ALN, afirmou, "não fui coadjuvante, nem apenas companheira. Fui militante, inclusive fui eu que levei o Carlos Russo, à militância [...]. Muitas vezes a trajetória da gente é deturpada, porque agimos na retaguarda". (OLIVEIRA, 2008).

Outras mulheres tiveram suas vidas completamente alteradas pelo casamento, como no caso Tereza Costa Rego, artista plástica, filha de uma tradicional aristocracia rural nordestina e mulher do militante comunista Diógenes de Arruda Câmara. Tereza fez parte de um perfil de mulheres que na definição de Olívia Rangel, atuaram movidas pelo coração (JOFFILY, 2005, p. 100). Não podemos, contudo, deixar de levar em conta que estas mulheres tiveram grande desprendimento e uma vontade de ferro para alterar seus destinos e abandonar seu bem estar econômico. Como Tereza afirmou, "fui educada para ser a boneca que enfeita o piano da sala de visitas. Acontece que um dia eu saltei do piano e fui embora". (REGO, 2012).

Há questões cruciais para se entender a militância da mulher que ultrapassam dimensões como centro e periferia ou as relações de gênero, entendidas aqui enquanto "essência" do feminino, ou em sua manifestação binária e essencialista (BUTLER, 2003, p. 27). A complexidade das relações sociais por outro lado - ao serem reconstituídas pelo trabalho de campo, tendo como objeto de análise os temas do vivido - raramente são verificadas na análise documental deste período. Os inquéritos realizados pela ditadura civil-militar constituem-se numa projeção sem fim de estereótipos inquisitoriais onde a relevância da participação política feminina é apresentada sempre na perspectiva da repressão, e na tentativa de desmobilizá-las politicamente. 
A orientação da ditadura era mesmo a de rebaixar a mulher militante, segundo Yara Gouvêa, que foi obrigada por Romeu Tuma e seu pai - que mantinha vínculos com o regime - a assinar um depoimento em que declarava ter sido induzida a participar da luta armada. (informação verbal) ${ }^{2}$. Muitas mulheres, contudo, utilizaram vantajosamente os apelos culturais da época para poderem atuar. Leta Alves, por exemplo, detida pelo delegado Fleury, ao ser questionada porque recebia tantos amigos comunistas de seu marido em casa, respondeu ao Encarregado do Inquérito, "é minha função como esposa". (ARQUIVO EDGARD LEUENROTH, 1970).

Gastone Lúcia Beltrão queria realizar treinamento guerrilheiro em Cuba, mas não tinha idade para deixar o Brasil. A solução encontrada foi o casamento. Como afirmou José Pereira seu marido, “O 'Mariga' achou a ideia [de se casar] ótima, pensava em mandar a 'menina de Alagoas' a Cuba, mas ela era menor (19 anos) e, se casássemos, ela ficaria emancipada, seria uma boa capa legal para nossa 'viagem de luade-mel"'. (PEREIRA, 2009) ${ }^{3}$.

Albertina Pedrassoli também jogaria habilmente com os estereótipos de gênero, durante suas duas prisões apresentando-se como a namorada sonsa do interior, que além de não possuir nenhum envolvimento político, desconhecia completamente a militância do namorado, Fernando Casadei Salles. Adotou após o casamento, o sobrenome do marido para despistar a repressão. Método simples, mas eficaz, pois nos registros da polícia nunca houve nenhuma Albertina Salles, ao passo que Albertina Pedrassoli era investigada. Foi com o nome de casada que Albertina Salles alugou muitos apartamentos para a Ação Libertadora Nacional (ALN).

Nunca o papel de amante, serviu tão bem às intenções da luta armada, quando uma distinta professora universitária de São Paulo com mais de trinta anos, mulher solteira e independente para os padrões da época, recebia o delegado Sérgio Paranhos Fleury em sua casa e ao mesmo tempo ajudava a retirar perseguidos políticos do país ou a abrigar estudantes após as passeatas. (MELONI, 2009; GOUVÊA, 2010).

Denise Crispim afirmou que foi em seu aparelho que o cônsul japonês foi alojado, após sequestro em março de 1970. Foi Denise quem, grávida, se encarregou da infraestrutura da casa, de alimentar o cônsul e de estabelecer os contatos com o exterior.

\footnotetext{
${ }^{2}$ GOUVÊA, Yara. Entrevista. [jul. 2010]. Entrevistador: Autora. Brasília, DF, 2010.

${ }^{3}$ PEREIRA, José. [Mensagem Pessoal]. Rio de Janeiro. Mensagem recebida por 〈Autora > em 10 de outubro de 2009.
} 
Como ela afirmou, "eu cozinhava, aprendi a fazer arroz com o Bacuri [Eduardo Collen Leite], porque minha mãe era uma péssima cozinheira". (informação oral) ${ }^{4}$. Nas memórias escritas pelo cônsul, Denise aparece como a "mulher invisível" (OKUCHI, 1991, p. 60).

Em situações de total desproporção de forças, a mulher se protegeu. Áurea Moretti disse sobre uma de suas sessões de tortura, "[...] uma vez quando um deles começou a me bater, eu menstruei, ele pensou que fosse hemorragia, eu fingi que desmaiei, ele começou a me ajudar a levantar, lavou meu rosto" [...]. (SILVEIRA, 2014, p. 65). Não foi a primeira presa a utilizar condições que favoreciam a preservação da vida. Estas práticas se configuraram como atos de resistência, em particular, quando esta resistência passou a um plano frontal como no interior da prisão. Há casos de mulheres presas que simularam loucura como no caso de Lays Machado (informação verbal) ${ }^{5}$, fingiram estar em estado demencial, ou mentiram, como afirmou Dilma Rousseff, respondendo à provocação do senador Agripino Maia (DEM),

A prisão é uma coisa que a gente se encontra nos limites da gente. [...] Eu fui barbaramente torturada e qualquer pessoa que ousar dizer a verdade para interrogadores compromete a vida dos seus iguais, entrega pessoas para serem mortas. Eu me orgulho muito de ter mentido, porque mentir na tortura não é fácil. Na democracia se fala a verdade, na tortura quem tem coragem, dignidade fala a mentira [...]. O que estava em questão era a minha vida e a de meus companheiros. Não há espaço para a verdade, é isto que mata na ditadura. O que mata na ditadura é que não há espaço para a verdade, porque não há espaço para a vida (ROUSSEFF, 2008).

Por trás de um sistema feito para excluí-las, estas mulheres souberam atuar. Este discurso oculto foi praticado pelas mulheres, o que mostra mais sua disponibilidade para a ação do que para a sujeição aos ditames morais da época e à ditadura.

Nos conflitos ocorridos em São Félix do Araguaia (MT) em março de 1972, em particular após a instalação da Companhia de Desenvolvimento do Araguaia (CODEARA), grande empresa agropecuária na cidade de Santa Terezinha, as mulheres de soldados e as prostitutas do lugarejo também se somaram à luta dos posseiros,

\footnotetext{
${ }^{4}$ REPARE Bem. Diretora: Maria de Medeiros. Brasil/Itália/Espanha: Projeto Marcas da Memória, Comissão de Anistia do Ministério da Justiça, 2012, 1h 45 min. DVD.

5 MACHADO, Lays. [dez. 2014]. Entrevistador: Autora. Maricá, RJ, 2014.
} 
repassando informações estratégicas, fornecendo alimentos e ajudando a desmobilizar a invasão da área pelas tropas do exército (informação verbal) ${ }^{6}$.

A militância precisava de aliados para ampliar sua infraestrutura. Havia sempre necessidade de quem fizesse estudos e levantamentos de regiões, conseguisse remédios, roupas, documentos. A ajuda poderia ser contar com um fiador de confiança para alugar uma casa, dar abrigo, ajudar a esconder documentação considerada comprometedora, dar fuga a alguém na saída de uma ação ou mesmo ajudar a atravessar a fronteira. Sirlene Bendazzoli foi presa em dezembro de 1968 sem ser denunciada. Frequentava o CRUSP e fazia parte de um grupo de discussão na USP sobre reforma universitária. Como relembra,

[...] Quando houve a invasão do CRUSP também não estava lá, mas me prontifiquei a buscar livros e outros objetos dos meus amigos, que haviam ficado nos apartamentos [...]. Tirei muita coisa, talvez demais para o gosto do Coronel Alvim que ocupava o local e acabei presa. Fiquei uns dias no próprio CRUSP, depois DEOPS, Tiradentes, completando 101 dias. Muito além dos estudantes acabei me aproximando de companheiros que viviam numa situação de muita violência. De jovenzinha inexperiente, fui passando a parceira numa luta pela sobrevivência e dignidade (CRUSP68, 2008).

Muitos outros exemplos de solidariedade partiram da população. A empregada doméstica de Maria da Conceição Sarmento escondeu Maria Valderez S. Coelho da Paz, sua filha, na favela do Rio Comprido, onde morava até que ela pudesse deixar o Brasil. Uma moradora de um prédio de Copacabana, por exemplo, teve o gesto de oferecer a Juarez Maia, militante da VAR-Palmares um prato de comida e um dinheirinho quando ele vivia uma semana de penúria perdido no Rio de Janeiro, por um encontro frustrado com um companheiro de organização. (MAIA, 2011, p. 306-312). A vizinha libanesa da casa de Lisete de Silvio se ofereceu para levá-la ao Líbano. Lá ela jamais seria encontrada pela polícia (SILVIO, 2010).

No dia do massacre da Praia Vermelha em setembro de 1966, quando muitos estudantes foram presos, Gastone Lúcia Beltrão conseguiu furar o cerco e entrar no Instituto Pinel. Segundo seu marido, José Pereira, "ficou deitada numa cama, coberta até a cabeça, com o acobertamento dos médicos e enfermeiros. A polícia entrou, procurou e não a encontrou". (PEREIRA, 2009).

\footnotetext{
${ }^{6}$ ROMERO, Francisco Negrini. Entrevista. [maio 2010]. Entrevistador: Autora. Piracicaba, SP, 2010.
} 
Outros exemplos desta ajuda espontânea abundam como cobradores de ônibus que impediram prisão de pessoas, donas de pensão que despistaram a polícia, vizinhos que ajudavam na comunicação entre militantes, passando recados, bilhetes, guardando correspondência. Na privacidade do lar, e evitando transitar à noite, estas pessoas também faziam vigília para espreitar a chegada da polícia.

A militância implicou numa reorganização da vida e em atitudes mínimas de proteção como apagar a luz de uma casa, permanecer no trabalho por mais tempo, evitar transitar pelos mesmos lugares. A sobrevivência estava no detalhe e foi justamente este detalhe que salvou vidas. A proteção da comunidade chegava também pelo viés religioso. Gente que acreditou estar prestando solidariedade através de rezas, de cartomantes, levando militantes em cultos de candomblé, em sessões espíritas, e apelando às divindades para "fechar o corpo", evitar a prisão e a morte, proteger armas e balas. Houve mesmo militantes que se converteram ao espiritismo no interior da prisão (informação verbal) ${ }^{7}$.

A música e a literatura de maneira sutil iam implicitamente boicotando a ordem militar, realizando um "trabalho psicossocial”. São inúmeros os exemplos de ajuda de escritores, cineastas e músicos à militância. A atriz Norma Bengel foi um elemento importante no sequestro do embaixador suíço. Era ela quem tinha acesso a casa onde ficou o embaixador e quem se encarregava de levar comida e remédios (GOUVÊA, 2010).

O músico Frederico Mendonça de Oliveira, Fredera, contou de seu apoio dado naqueles anos,

[...] Sobre nosso enfrentamento com a ditadura. Se não saímos no tapa nas ruas, fizemos outra forma de resistência - que, garanto, não foi nada mole. Tudo que fizemos foi contra eles, contra o lobby deles, contra o triste destino que tentaram - e conseguiram - nos impor. Quanto a meu trabalho de apoio, resume-se a ter dado abrigo a uma ativista que atendia por Waleska [Waleska Pinto] e que "colou" no show da Gal em 1971 no Opinião, Deixa Sangrar. Estava como que se infiltrando ou agregando. Tinha muita fala teórica, era gaúcha, acabamos muito amigos - eu dava muita atenção ao discurso dela, era permeável a isso, ao contrário de gente como o Wagner (Tiso), que ridicularizava a militância, especialmente de mulheres - e íamos vivendo a temporada quando, numa bela noite, ela apareceu linda, toda produzida, de tailleur, ela que andava de bata indiana, sandálias e calças jeans sem cinto. Intrigado, chegando ao teatro e vendo-a toda madame, perguntei qual era, e ela informou que caíra o endereço dela,

\footnotetext{
${ }^{7}$ ARY, Wilma. Entrevista. [nov. 2008]. Entrevistador: Autora. São Paulo, 2010.
} 
que estava na clandestinidade, sem onde ficar. [...] E eu a levei comigo para meu apartamento, onde ela ficou por mais de um mês [...]. Curiosamente jamais me incluíram em nada de nada. Eu tinha ligações com músicos egressos de atividade estudantil, sabia de histórias de gente em atividade ou que caía ou entrava na clandestinidade, estava sempre de olho. [...] (OLIVEIRA, 2012)

Se o amor definiu e modificou a vida política de algumas mulheres, em alguma medida ele produziu outros atos de amor encontrados na experiência de mães, maridos, esposas. José Pereira se entregou à repressão para encontrar sua mulher,

[...]. Estava esperando ser preso e morto, já que fazia parte dos condenados à morte por ter pertencido ao III Exército da ALN. A Gastone estava presa e eu não conseguia ter qualquer notícia a respeito [...]. Botei na cabeça que ia fazer muito melhor tentando localizar a Gastone do que ficar esperando a minha hora de ser preso e morto [...]. Meu pai falou para eu me entregar [...]. No início não aceitava nem pensar num absurdo destes, depois comecei a achar que seria a única forma de fazer a Gastone aparecer, nem que fosse para sermos torturados juntos. Assim me entreguei no dia 08/05/72, dizendo que a guerra para mim tinha acabado e que a única coisa que queria era saber da Gastone. Fiquei preso no Batalhão de Guardas, fui muito ameaçado e tratado como terrorista filho da puta. Na primeira visita que tive dos meus pais, uns 15 a 30 dias depois de preso, recebi das mãos de meu pai um pedaço de papel onde trazia "Cemitério de Perus - Sepultura ......, Quadra........". (PEREIRA, 2009).

Se no caso de José Pereira nos deparamos com o testemunho de um viúvo, muitas mulheres também enviuvaram naqueles anos. Sobre suas trajetórias também permanece um discurso oculto por trás do que Elizabeth Jelin chamou de "familismo". Durante a ditadura, como ela afirma, tanto os militares como o movimento de direitos humanos utilizaram a matriz familiar para interpretar seu lugar no confronto político (JELIN, 2007, p. 39). Hoje, tanto mães como esposas passam a enfatizar sua condição de militante, recuperando um protagonismo perdido na história e mostrando, que a despeito de seus vínculos de sangue, partilhavam o mesmo projeto político.

Isso não quer dizer também que como mães, estas mulheres não foram grandes parceiras na comunicação entre os militantes, dando algum tipo de sustentação à luta, quando não se integraram de fato a ela. Se os policiais prendiam seus filhos, invadiam suas casas, chantageavam seus parentes, destruíam e confiscavam objetos, as mães 
davam o troco: ajudavam os clandestinos, criavam dificuldades ao regime, desprezavam as consignas da ditadura, iam aos tribunais denunciar o desaparecimento de alguém, escreviam cartas aos generais, ajudavam pessoas a saírem pela fronteira. As mães representaram outro perfil de mulheres que compuseram igualmente a resistência naqueles anos.

A escola e o trabalho também serviram como espaços para estas mulheres atuarem. Arlete Diogo, por exemplo, orientadora do centro cívico da escola onde lecionava OSPB (Organização Social e Politica do Brasil) e Educação Moral e Cívica em São Paulo, desenvolvia atividades paralelas de militância, utilizando o espaço da sala de aula para se contrapor ao ufanismo dos militares, na tentativa de criar um espírito crítico nos alunos (informação oral) ${ }^{8}$. Marília Guimarães, proprietária de um colégio particular no Rio de Janeiro, afirma que o colégio passou a desempenhar o papel de uma célula da VAR-Palmares, na medida em que todo o material gráfico da organização era produzido pelo seu mimeógrafo (informação oral) ${ }^{9}$.

Tânia Mendes realizava estágio na gerência de marketing da PIRELLI e contribuiu com informações para a ALN sobre o financiamento de empresários ao DOICODI (informação oral) ${ }^{10}$. Recém-formada no curso de contabilidade, Darci Miyake se empregou no escritório de contabilidade do senador Carvalho Pinto, para a obtenção de informações ${ }^{11}$. Wilma Ary porta voz do movimento estudantil no jornal Folha de $S$. Paulo cobria as agitações de rua produzindo rapidamente matérias para as outras agências de notícias, antes que a versão da repressão reinasse na imprensa escrita (informação oral) ${ }^{12}$.

Tereza Poggi italiana radicada no Brasil desde 1965 para participar dos trabalhos sociais desenvolvidos por Dom Hélder Câmara deu apoio em São Luís do Maranhão a pessoas perseguidas, escondendo camponeses em sua casa, os ajudando com recursos médicos e financeiros e permitindo o desenvolvimento de um trabalho político junto às quebradeiras de babaçu na região (informação oral) ${ }^{13}$.

\footnotetext{
${ }^{8}$ DIOGO, Arlete Lopes. Entrevista [jun. 2010]. Entrevistador: Autora, São Paulo, 2010.

${ }^{9}$ GUIMARÃES, Marília. Entrevista [mar. 2009]. Entrevistador: Autora, Rio de Janeiro, 2009.

${ }^{10}$ MENDES, Tânia Rodrigues. Entrevista [maio 2010]. Entrevistador: Autora, São Paulo; 2010.

${ }^{11}$ MIYAKE, Darci Entrevista [ago. 2010]. Entrevistador: Autora, Indaiatuba, SP, 2010.

${ }^{12}$ ARY, Wilma. Entrevista [nov. 2008]. Entrevistador: Autora. São Paulo, 2010.

${ }^{13}$ POGGI, Tereza. Entrevista [jan. 2009]. Entrevistador: Autora. Recife, PE, 2009.
} 
As relações de amizade também mobilizaram redes de ajuda à militância armada, como no caso de Nair Benedicto, que emprestava sua casa na Vila Mariana para reuniões dos dirigentes da $\mathrm{ALN}^{14}$, no de Sandra Brisolla, que cedeu a casa de veraneio de sua família em São Sebastião para esconder militantes que participaram do sequestro do embaixador americano Charles Elbrick ${ }^{15}$ ou de Maria Lúcia Alves Ferreira, a Malu, que ajudou a embarcar gente para Cuba, transportando Antônio Benetazzo e Arno Preis ao aeroporto ou dirigindo para amigos até Rio de Janeiro ou Paraná na execução de tarefas para a Ação Libertadora Nacional (ALN) ${ }^{16}$.

\section{Considerações Finais}

Muitos outros casos poderiam ser citados, que servem como exemplo destas redes de ajuda ou solidariedade e ilustram de que maneira elas atuaram, o que excede os limites deste texto. Mais importante é dizer que a consolidação destes apoios dependeu da ousadia, da disponibilidade e da criatividade destas mulheres que não se acomodaram ao papel que lhes foi atribuído, mas souberam transformá-lo. A militância ocupou todos os espaços de sua vida, a escola, o trabalho, a família, seus momentos de lazer.

Os atos de cooperação destas mulheres fizeram parte de uma luta objetiva e subjetiva, operando no campo social enquanto um movimento fluido, espontâneo e dependente do contexto histórico, da formação política ou simplesmente da vontade de ajudar, pois a forma de organização é tanto um produto da necessidade política, quanto uma escolha pessoal. Mesmo que seus gestos não enfrentassem de maneira explícita a ordem militar, nem estivessem inscritos numa ideologia política claramente definida, eles tiveram o propósito de proteger e defender a vida.

Para concluir, se a dominação não persiste pela inércia, seu exercício produz diferentes respostas e outras formas de consolidação da oposição. Os pequenos gestos, mais do que ser considerados como uma "agressão ritualizada" ou fatores de manutenção de um status quo de uma ordem institucional, fizeram parte deste discurso oculto. E se este é um discurso interno, do qual muitas mulheres se serviram, ele

\footnotetext{
${ }^{14}$ BENEDICTO, Nair. Entrevista [jun. 2010]. Entrevistador: Autora. São Paulo, 2010.

${ }^{15}$ BRISOLLA, Sandra. Entrevista [out. 2008]. Entrevistador: Autora. Campinas, SP, 2008.

${ }^{16}$ FERREIRA, Maria Lúcia Alves [ago. 2010]. Entrevistador: Autora, São Paulo, 2010.
} 
também é dialógico. Como afirmou Scott, "a resistência simbólica velada às ideias de dominação não se pode separar das lutas concretas. O discurso oculto se realiza em conjunto de estratégias tão concretas como discretas cujo fim é minimizar a apropriação. Ele é o político em sua forma não declarada”. (SCOTT, 2000, p.222).

\section{Referências}

AQUINO, M. A. de. Golpe de Estado de 1964. Que Estado, País, Sociedade são esses? Revista Projeto História, São Paulo, (29) tomo 1, p. 87-105, dez. 2004.

ARQUIVO EDGARD LEUENROTH, AEL-UNICAMP. Acervo Brasil Nunca Mais, Processo n. 537, p. 100, Rio de Janeiro, 02 jul. 1970.

ARY, Wilma. Entrevista. [nov. 2008]. Entrevistador: Autora. São Paulo, 2010.

BEVERLEY, J. Revista de Critica Literária Latino Americana. Ano XIII, n. 25, Lima, ler. Semestre de 1987, p. 7-16.

BUTLER, J. Problemas de gênero: feminismo e subversão da identidade. Tradução de Renato Aguiar. Rio de Janeiro: Editora Civilização Brasileira, 2003.

CRUSP68. Memórias, Sonhos e Reflexões. Coletânea Documental de ex-cruspianos. Pré-edição comemorativa. São Paulo: eBooksBrasil, 2008.

GINSBURG, C. et al. A Micro Historia e Outros Ensaios. São Paulo: Difel, 1991.

GOUVÊA, Yara. Entrevista. [jul. 2010]. Entrevistador: Autora. Brasília, DF, 2010.

JELIN, E. Víctimas, familiares y ciudadanos/as: las luchas por la legitimidad de la palabra Cadernos Pagu n. 29, p. 37-60, julho/dezembro de 2007.

JOFFILY, O. R. Esperança Equilibrista: Resistência feminina à ditadura militar no Brasil (1964-1985). 2005. Tese de Doutorado Ciências Sociais. Universidade Católica, PUC-SP, São Paulo, 2005.

LE GOFF, J. História e memória. Campinas, SP: UNICAMP, 2005.

MAIA, J. Spaghettilândia. FERRER, E. (Org.). 68 a geração que queria mudar o mundo: relatos. Brasília: Ministério da Justiça, Comissão de Anistia, 2011, p. 306-312.

MARIA, Ignez. Entrevista. [16/12/2013]. Martinha: “Ainda não vivemos uma democracia plena". Entrevistadores: Lorena Paim e Nubia Silveira. Disponível em: < http://www.sul21.com.br/jornal/martinha-ainda-nao-vivemos-uma-democracia-plena/ $>$. Acesso em: 11 jul. 2014.

MELONI, C. 1968. O tempo das escolhas. São Paulo: Nova Alexandria, 2009.

MONTARROYOS, S. de. Réquiem por Tatiana: memórias de um tempo de guerra e de uma descida aos infernos. Recife: Cepe, 2013.

OLIVEIRA, Vera Engracia Gama de [Mensagem Pessoal], Porto Velho, Rondônia. Mensagem recebida por « Autora > em 12 de novembro de 2008.

OLIVEIRA, Frederico Mendonça. [Mensagem Pessoal]. Alfenas, Minas Gerais. Mensagem recebida por « Autora > em 09 de junho de 2012. 
OKUCHI, N. O sequestro do diplomata: memórias. São Paulo: Estação Liberdade, 1991. PAZ, Carlos Eugênio. Entrevista. [jan. 2013]. Entrevistador: Autora. Paris, 2013. PEREIRA, José. [Mensagem Pessoal]. Rio de Janeiro. Mensagem recebida por « Autora > em 10 de outubro de 2009.

REGO, Tereza Costa. Entrevista. [2/03/2012]. Uma mulher em três nomes. Entrevistadora: Mazé Leite. Disponível em: 〈http://www.vermelho.org.br/noticia_print. php?id_noticia=176987\&id_secao=11 . Acesso em: dez. 2014.

REPARE Bem. Brasil. Diretora: Maria de Medeiros. Itália/Brasil/Espanha: Projeto Marcas da Memória, Comissão de Anistia do Ministério da Justiça, 2012, 1h 45 min. DVD.

ROMERO, Francisco Negrini. Entrevista. [maio 2010]. Entrevistador: Autora. Piracicaba, SP, 2010.

ROUSSEFF, Dilma. Audiência na Comissão de Infraestrutura do Senado, Brasília, 07 de maio de 2008. Disponível em: 〈http://www.youtube.com/watch?v=Tiyezo1fLRs〉. Acesso em 08 de maio 2008.

SCOTT, J. Los dominados y el arte de la resistencia. Discursos Ocultos. México: Ediciones Era, 2000.

SILVIO, Lisete. Entrevista. [ago. 2010]. Entrevistadora: Autora. São Paulo, 2010. TOURAINE, A. Sexo, Gênero, Sujeito. [nov. 2004]. Entrevistadora: Miriam Adelman. Revista de Sociologia e Política, Curitiba, p. 169-174, nov. 2004. 